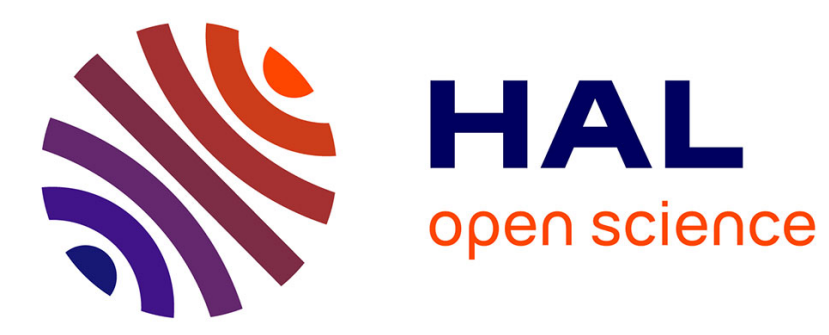

\title{
Service discovery in ubiquitous environments : approaches and requirements for context-awareness
}

\author{
Mohamed Sellami, Samir Tata, Bruno Defude
}

\section{To cite this version:}

Mohamed Sellami, Samir Tata, Bruno Defude. Service discovery in ubiquitous environments: approaches and requirements for context-awareness. SEMANTICS4WS 2008: 3rd International Workshop in Advances in Semantics for Web Services, Sep 2008, Milan, Italy. pp.516 - 522, 10.1007/9783-642-00328-8_52. hal-01380993

\section{HAL Id: hal-01380993 https://hal.science/hal-01380993}

Submitted on 13 Oct 2016

HAL is a multi-disciplinary open access archive for the deposit and dissemination of scientific research documents, whether they are published or not. The documents may come from teaching and research institutions in France or abroad, or from public or private research centers.
L'archive ouverte pluridisciplinaire HAL, est destinée au dépôt et à la diffusion de documents scientifiques de niveau recherche, publiés ou non, émanant des établissements d'enseignement et de recherche français ou étrangers, des laboratoires publics ou privés. 


\title{
Service Discovery in Ubiquitous Environments: Approaches and Requirement for Context-Awareness
}

\author{
Mohamed Sellami, Samir Tata, and Bruno Defude \\ Institut TELECOM, CNRS UMR SAMOVAR, Evry, France, \\ \{mohamed.sellami, samir.tata, bruno.defude\} @it-sudparis.eu,
}

\begin{abstract}
We are living a democratization of ubiquitous environments offering a great number of services. Different devices, having different technical capacities access those services. Such environment requires an effective service discovery approach. In this paper, we start with a study of some existing service discovery approaches. Then we introduce a semantic and context-aware service discovery approach. We propose to distribute services registries in a $\mathrm{P} 2 \mathrm{P}$ network. The registries will be structured according to the capacities and semantics of the services. To describe capacity and semantic of a service, we annotate its WSDL description.
\end{abstract}

Key words: Web Service discovery, Semantic and Capacity annotation, $\mathrm{P} 2 \mathrm{P}$ Web service registries.

\section{Introduction}

In the service-oriented model, service discovery is generally based on a centralized registry. Service providers begin by publishing their services descriptions in that registry. Then, service consumers who want to use a service have to perform some queries on that registry to find the desired service. This is usually done using the UDDI standard [1].

This discovery method has some limitations. Indeed, it may return a great number of services. So a human intervention is needed for service selection. Moreover, the obtained services do not necessarily fit the service consumer needs. This is due to the lack of expressiveness of both service descriptions and queries. In addition, even after finding an appropriate service, there is always a risk that it is not available at invocation especially in ubiquitous environment.

In our work, we are interested in service discovery especially in ubiquitous environments. Such kind of environments includes a lot of services offering devices, inter-connected with different users. Usually, the different service consumers access those services through different devices (PDA, Smartphone, etc.). So, in addition to the above mentioned problems (insufficient service description, low search accuracy), the problem of context ${ }^{1}$ incompatibility between a service and

\footnotetext{
${ }^{1}$ Any information that can be used to characterize the situation of an entity. An entity is a person, place, or object that is considered relevant to the interaction between a user and an application, including the user and applications themselves[2].
} 
the user's context arises. Therefore, context must be taken into account for service discovery in such environment.

In this paper, we introduce our approach towards semantic and context-aware service discovery in ubiquitous environments. For this aim, we use a structured P2P network of registries. The registries are structured according to the capacity and semantic domain of the published services. The remainder of this paper is organized as follows. Section 2 describes and compares some service discovery approaches. Section 3 introduces our approach for Web service discovery. Finally, Section 4 concludes this paper.

\section{Approaches for service discovery}

Current Web service discovery approaches can be classified as centralized vs. decentralized and syntactic vs. semantic. It is obvious that centralized and syntactic approaches do not fit with nowadays pervasive environments. Distributed and semantic approaches are more appropriate for those environments.

Distributed approaches are mainly based on P2P systems. In pService [3], the semantic of a service is described using WSDL-S [4]. The WSDL-S most important information (e.g. service name) is hashed to a Chord network [5] and the others to a Skip Graph [6] that accelerates and facilitates data querying while preserving the information structure. So, the discovery process will be done in two phases. The work presented in [7] is based on the use of registries federations. A federation is a set of cooperating and autonomous registries serving a specified business domain. By structuring the registries network into federations, the number of queried registries in a discovery process is reduced. Semantic annotations for WSDL are used to describe service semantics.

Also works in $[8,9,10]$ structure their distributed service registries. In [10], to semantically describe a service's functionalities, OWL-S [11] is used. The services are distributed according to textual description contained in their WSDL $<$ documentation $>$ tag. At the service discovery, a query is first routed to the most similar group. Then, a matching between the user's needs and the peers in that group is realized. To achieve this, the query is flooded to all peers in that group. The registries structure in $[8,9]$ is realized according to the semantic of the published services they contain.

In $[12,13]$, context-aware service discovery is used. In [13], a centralized service discovery architecture is proposed. It uses a context-aware service registry (i.e. enriched with context descriptions). To discover a service, two queries are used $Q_{u s r}$ and $Q_{c x t}$. $Q_{u s r}$ extracts services using keywords specified by a service consumer. Those services will be transmitted to the context-aware service registry. $Q_{c x t}$ is then used to choose the services matching the consumers context. In [12] the authors propose a distributed architecture based on GloServ [8] that classifies services according to their business domain and associates a context-aware agent to each class. When an agent receives a query, it searches the appropriate classes for it, and forwards the query to the agents of those classes. One of those agents will then ask the user for his/her context and search the appropriate service. 
We present a comparison of the presented approaches in Fig. 1. Those service discovery approaches are compared based on the following criteria: distribution, context-awareness, structuring criteria, ontology language and Web service description language. We notice that approaches that structure their registries do that according to the semantic. We propose to do it according to both semantic and capacity. By capacity of a service we mean the context in which a service can be used. Some works separate the semantic of a service from it WSDL description while others are putting it together by annotating the WSDL service description. In $[12,13]$ we put Not specified for Web service description language as it was not specified in those works which are interested in other aspects. For our work, we propose to group together functional, semantic and capacity service description by annotating its WSDL description. By semantic service description we mean the semantically added value to its functional description.

\begin{tabular}{|l|c|c|c|c|c|c|}
\hline References & {$[3]$} & {$[7]$} & {$[9]$} & {$[10]$} & {$[12,8]$} & {$[13]$} \\
\hline Distributed & $\mathrm{X}$ & $\mathrm{X}$ & $\mathrm{X}$ & $\mathrm{X}$ & $\mathrm{X}$ & $\mathrm{X}$ \\
\hline Context-aware & & & & & $\mathrm{X}$ & $\mathrm{X}$ \\
\hline Structuring criteria & Not structured & Semantic & Semantic & Keyword & Semantic & Not structured \\
\hline Ontology description language & OWL & OWL & OWL & OWL & OWL & Not specified \\
\hline WS description language & WSDL-S & $\begin{array}{c}\text { WSDL- } \\
\text { Annotation }\end{array}$ & $\begin{array}{c}\text { WSDL }+ \\
\text { OWL-S }\end{array}$ & $\begin{array}{c}\text { WSDL }+ \\
\text { OWL-S }\end{array}$ & Not specified & Not specified \\
\hline
\end{tabular}

Fig. 1. Some semantic discovery approaches

\section{Toward a semantic Web service discovery approach in structured $\mathrm{P} 2 \mathrm{P}$ registries}

The use of semantic within the service discovery process ensures a better discovery thanks to more meaningful descriptions, usable by software agents. Another interesting direction to follow in our research is registries distribution. This can allow avoiding the "single point of failure" of the centralized approaches. To semantically describe a service, we annotate his WSDL description using SAWSDL. This way, a service functional description and its semantic are expressed in the same model. This way, a single information source (for functional description and its semantic) is handled during service publication and discovery.

When distributing service registries, a $\mathrm{P} 2 \mathrm{P}$ approach is used which is appropriate to dynamic environments. Also, many existing effective $\mathrm{P} 2 \mathrm{P}$ routing algorithms can be adapted and adopted to the needs of Web service discovery. Another important aspect that also must be considered during service discovery process is context-awareness. In fact, with the emergence of pervasive computing, service semantic is not sufficient to satisfy a service consumer. So, the capacity of a service must be taken into account in service discovery process. Hence the idea for our work. Our objective is to define a semantic and context-aware Web service discovery approach in a distributed environment. In order to achieve such a goal, we have to:

1. Propose annotations for the WSDL service description. Those annotations should deal with functional, semantic and capacity aspects of the services. 
2. Determine how services descriptions will be distributed in a P2P registries network.

3. Define a query language for service discovery. The queries must allow describing the user's need in terms of semantic description and context information.

4. Propose an algorithm for matching queries and the published services descriptions.

In the following sub-sections, we further explain the above four points.

\subsection{Representing capacity and semantic of a service}

To model the semantic and capacity of a service, we annotate it WSDL description. To realize this, SAWSDL can be used to semantically describe the service functionalities. To describe the service capacity, we propose to extend SAWSDL by adding a capacity attribute to the operations descriptions. For further detail, please refer to our previous work [14]. Let's call the obtained description CSAWSDL standing for Capacity and Semantic Annotations for WSDL. The CSAWSDL description contains, the semantic functional description $(S D)$ of the service and the capacity description $(C D)$.

\subsection{Service description distribution}

In several contributions, registries and sometimes services (we mean services and their descriptions who are deployed on the same server), are distributed as a $\mathrm{P} 2 \mathrm{P}$ network. Most of them tried to put services (or services descriptions) offering similar functionalities $[9,15,7,10]$ in the same registry (or clusters). Thus, a service discovery is done in two phases: (1) Find the appropriate services using a semantic search for example, (2) Choose between those services the one(s) who fit the user's needs and context. In addition, we propose to structure the registries according to service capacity. In fact, in pervasive environments, the Web service access can be done through different devices, having different technical characteristics. So, grouping services having similar capacities will enhance service discovery by limiting the search domain and targeting search queries to the right services group.

Meanwhile, structuring registries according to their semantic domains is still interesting. Therefore, we propose to take into account the semantic and capacity aspects of services when publishing them into distributed registries (Fig.2). When structuring registries by the capacities and semantics of their services, discovery queries will be directly targeted to the right registries group.

Our $\mathrm{P} 2 \mathrm{P}$ registries network is structured in the beginning according to the capacities of the services published in the registries. Indeed, a mobile service consumer, looking for a service, is firstly interested in services that fit his/her context. When structuring the registries network, we obtain different registry capacity groups. If the number of services in a capacity group is not very large, there is no need to further structure it according to the semantic of the published services.

Otherwise, when the number grows up, another structuring using the semantic is beneficial. In fact, executing the matching algorithm on a big number of services will be cost expensive. So, in this case, the obtained groups are also 
structured into sub-groups, according to services semantic. This structuring, according to capacities and semantics, ensures that the matching algorithm (see Section. 3.4) will be executed on a reasonable number of services.

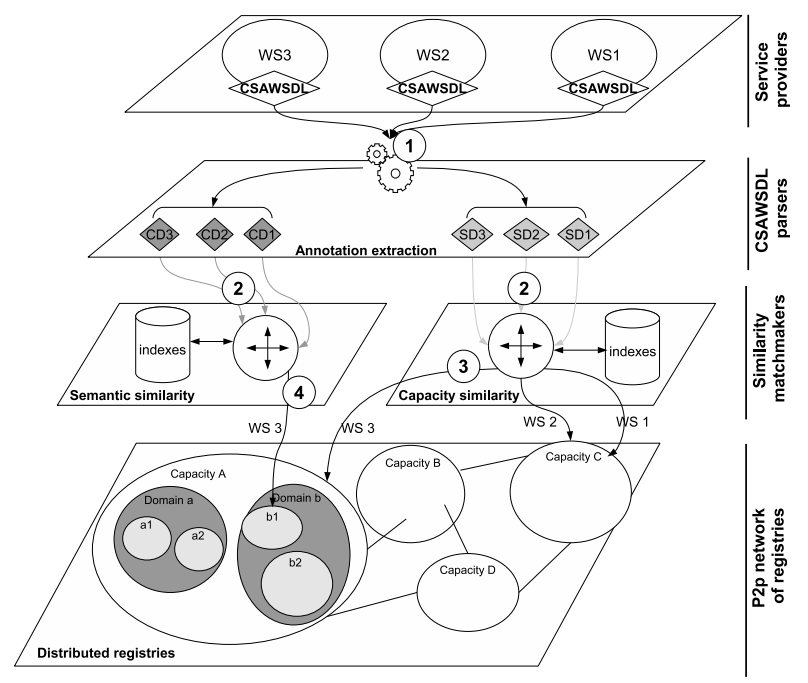

Fig. 2. Service publication according to its semantic and capacity

\subsection{Querying for a service}

To discover a Web service, a service consumer has to represent its needs in terms of an annotated WSDL query. We use CSAWSDL to model a user's query and request elements (like inputs, outputs, etc.). In addition, we annotate the WSDL $<$ operation $>$ element with a context attribute that describes the name and value of context. That's how, we represent the user's context in the query.

\subsection{The matching algorithm}

To discover a service, a matching algorithm is used. It evaluates the similarity between a user's query and Web service descriptions. Queries and descriptions are both written in CSAWSDL. We use our matching algorithm introduced in [14]. In this algorithm, the matching result between two operations is computed from the matching of concepts of inputs, outputs, preconditions, effects, and operations as well as the matching between user's contexts and service capacities.

\subsection{Process of service publication and discovery}

Let's take the example of a service provider going to publish its service. It starts with creating his/her CSAWSDL service description (see Section 3.1). The group in which the description will be published is determined by the capacity and semantic similarity matchmakers. So, to publish a service description, the capacity similarity matchmaker selects the group to which belongs the service. This is achieved by calculating the similarity factor between the capacity description 
of the service and the different registries groups. Then, the adequate semantic group is chosen by using the capacity similarity matchmaker (see Fig. 2). Service discovery is done similarly to the service publication.

\section{Conclusion and open issues}

In this paper we proposed an approach for semantic Web service discovery based on structured P2P registries. We describe the semantic and capacity of a service by annotating WSDL (CSAWSDL). The structure of our registries network is created according to the services capacities and semantics. Initially, we structure with services capacities and if necessary, if the number of services grows up, with semantic. Thus we ensure that the matching algorithm will be executed on a reasonable number of services.

For future works, we envisage to determine the threshold of service in which our matching algorithm cost is acceptable. Thus, we can know when to further structure the registries network in order to preserve a reasonable cost for the matching. We also intend to define a notification system that detects the unavailable registered services to maintain the registries consistency and reliability. Indeed, in ubiquitous environments, service location can change. That's why registries can contain a lot of descriptions for unavailable services.

\section{References}

1. UDDI Technical Committee: "Universal Description,Discovery and Integration (UDDI)". (http://www.oasisopen.org/committees/uddi-spec/)

2. Abowd, G.D., Dey, A.K., Brown, P.J., Davies, N., Smith, M., Steggles, P.: Towards a better understanding of context and context-awareness. (In: HUC'99)

3. Lv, W., Yu, J.: pservice: Peer-to-peer based web services discovery and matching. (In: ICSNC'07))

4. Akkiraju, R., Farell, J., Miller, J.A., Nagarajan, M., Sheth, A., Verma, K.: Web service semantics - wsdl-s. Technical report (2005)

5. Stoica, I., Morris, R., Karger, D., Kaashoek, M.F., Balakrishnan, H.: Chord: A scalable peer-to-peer lookup service for internet applications. (In: SIGCOMM'01)

6. Aspnes, J., Shah, G.: Skip graphs. (In: SODA'03)

7. Sivashanmugam, K., Verma, K., Sheth, A.: Discovery of web services in a federated registry environment. (In: ICWS'04)

8. Arabshian, K., Schulzrinne, H.: Gloserv: Global service discovery architecture. In: MobiQuitous. (2004)

9. Ayorak, E., Bener, A.B.: Super peer web service discovery architecture. (In: ICDE)

10. $\mathrm{Xu}, \mathrm{B}$. , Chen, D.: Semantic web services discovery in p2p environment. (In: ICPPW'07)

11. The OWL Services Coalition: OWL-S: Semantic Markup for Web Services. http://www.daml.org/services/owl-s/1.1/ (2004)

12. Arabshian, K., Schulzrinne, H.: Distributed context-aware agent architecture for global service discovery. (In: SWUMA'06)

13. Doulkeridis, C., Loutas, N., Vazirgiannis, M.: A system architecture for contextaware service discovery. Electr. Notes Theor. Comput. Sci. 146 (2006)

14. Ould Ahmed M'Bareck, N., Tata, S., Maamar, Z.: Towards an approach for enhancing web services discovery. (In: WETICE'07)

15. Schmidt, C., Parashar, M.: A peer-to-peer approach to web service discovery. World Wide Web 7 (2004) 